\title{
Partisipasi Masyarakat dalam Ekologi Pembangunan Permukiman di Kampung Gunung Anyar Surabaya
}

\author{
Kusumastuti, Srie Subekti, Sungkono, Endang Sri Sukaptini \\ Program Studi Diploma Teknik Sipil FTSP ITS, Surabaya \\ Email: kusumastuti.its@hotmail.com
}

\begin{abstract}
The ecology of settlement refers to the basic needs of human and it plays a very strategic role in building the national identity. For this, the ecology of settlement needs to be nurtured and developed for the sustainability and enhancement of life and livelihoods. Environmental management is one of settlement ecology. This research is designed for enhancing the participation of community in settlement ecology and for improving the quality of settlement environment such as reforestation, solid waste management, wastewater treatment, waste, water and sanitation. The research hypothesis was testing by means of Chi-Square in order to enhance the community participation and the quality of settlement environment. Meanwhile, data in this research was obtained through questionnaires, direct observation and interviews concerning with the physical condition of settlement environment. The result of this study then shows that the improvement of environment quality is highly determined by community participation and Government of Surabaya in integrally implementing the development programs in urban areas
\end{abstract}

Keywords: ecological settlement, community participation, quality of environment settlement.

Abstrak

Ekologi permukiman merupakan kebutuhan dasar manusia serta mempunyai peran yang sangat strategis dalam pembentukan kepribadian bangsa, maka perlu dibina dan dikembangkan demi kelangsungan serta peningkatan kehidupan dan penghidupan masyarakat. Pengelolaan lingkungan permukiman merupakan salah satu ekologi permukiman. Tujuan penelitian ini adalah meningkatkan partisipasi masyarakat dalam ekologi permukiman, meningkatkan kualitas lingkungan permukiman, seperti penghijauan, pengelolaan limbah padat, IPAL, sampah, air bersih, dan sanitasi lingkungan. Hipotesis penelitian diuji dengan menggunakan Chi-Square untuk meningkatkan partisipasi masyarakat dan kualitas lingkungan permukiman. Data didapatkan melalui daftar pertanyaan, pengamatan langsung dan wawancara mengenai kondisi fisik lingkungan permukiman. Hasil penelitian ini menunjukkan bahwa peningkatan kualitas lingkungan dipengaruhi oleh partisipasi masyarakat, serta pemerintah Kota Surabaya dalam melaksanakan program-program pembangunan wilayah perkotaan secara terpadu.

Kata Kunci: ekologi permukiman, partisipasi masyarakat, kualitas lingkungan permukiman.

\section{Pendahuluan}

Kepadatan lingkungan permukiman seperti di kampung Gunung Anyar memang banyak terjadi di Surabaya, yang menjadi permasalahan dalam pembangunan ekologi permukiman adalah apakah kawasan tersebut telah berwawasan lingkungan, supaya terwujud perumahan dan permukiman yang layak dalam lingkungan yang sehat, serasi dan teratur. Kampung Gunung Anyar merupakan lingkungan suatu masyarakat yang sudah mapan, yang terdiri dari golongan berpenghasilan rendah dan menengah, yang pada umumnya tidak memiliki prasarana, utilitas dan fasilitas sosial yang cukup, baik jumlah maupun kualitasnya.

Jurnal APLIKASI: Media Informasi \& Komunikasi Aplikasi Teknik Sipil Terkini Halaman 57 
Dengan kondisi prasarana lingkungan yang cukup, maka diperlukan partisipasi masyarakat dalam pengelolaannya. Untuk meningkatkan partisipasi masyarakat dalam pengelolaan prasarana lingkungan, maka diperlukan pula peran pemerintah Kota Surabaya. Mengingat jumlah kampung di Surabaya sangat banyak dan heterogen, maka salah satu usaha yang telah dilakukan oleh pemerintah Kota Surabaya adalah dengan mengadakan lomba Surabaya Cantik Green and Clean yang diadakan setiap tahun. Untuk mewujudkan kampung yang asri dan pengelolaan lingkungan yang baik, warga terus diberi semangat, sosialisasi, dan motivasi agar warga berpikir bahwa ini bukan untuk dirinya sendiri, tapi juga demi lingkungan. Hal ini dibutuhkan perjuangan dan sosialisasi yang intensif untuk menggerakkan kesadaran warga kampung.

Di kawasan kampung RW IV Gunung Anyar, jumlah pengangguran sebelumnya mencapai $40 \%$. Namun beragam upaya dilakukan untuk menekan angka pengangguran tersebut, sehingga sekarang menjadi sekitar 5\%. Jumlah pengangguran yang besar bisa menjadi momok tersendiri. Dampaknya, rawan terjadi tindak kejahatan dan kampung tidak terawat. Perlahan-lahan beragam pelatihan digencarkan termasuk pemahaman kepada warga untuk bisa bangkit. Saat ini, angka pengangguran dapat ditekan; wargapun memiliki kegiatan atau mata pencaharian, sehingga mereka sekarang berani membina rumah tangga. Selain menekan angka pengangguran, warga juga memanfaatkan lahan kosong, dimana lahan tersebut sebelum- nya sangat kumuh, banyak rongsokan ditaruh di lahan tersebut. Sehingga terkesan kusam dan kotor, akhirnya lahan tersebut dirombak menjadi kebun. Hasilnya, lahan tersebut kini berubah, tidak lagi kusam dan kotor. Warna hijau dan warna-warni bunga mendominasi diberbagai sisi, sehingga terkesan sejuk dengan jaring-jaring yang kerap dijumpai pada green house. Di kebun itu tersedia berbagai jenis tanaman, mulai aneka toga hingga urban farming, diantaranya, cabai, tomat, terong dan pare. Ada juga berbagai tanaman bunga dan jenis krokot. Semuanya ditanam dalam ratusan pot mini, hal ini merupakan tempat pembibitan. Pagi dan sore tanaman tersebut disiram dengan air hasil IPAL atau hasil water treatment. Ketika sudah tampak besar, tanaman itu didistribusikan kepada warga ditata di sepanjang gang perkampungan. Tanaman seakan tidak pernah habis, karena setiap tumbuh besar bisa dilakukan pembibitan.

Dari penjelasan di atas, tujuan dari penelitian ini adalah meningkatkan partisipasi masyarakat dalam ekologi permukiman dan upaya untuk meningkatkan kualitas lingkungan permukiman.

\section{Metodologi}

Penelitian ini merupakan kajian kepustakaan berupa review literatur yang mendukung data primer. Teknik pengumpulan data primer diperoleh dari wawancara, kuesioner, dan observasi. Sedangkan pengumpulan data sekunder diperoleh dengan melakukan studi pustaka. 
Tujuan dari analisa data yang terkumpul untuk mengetahui keterkaitan antara satu data dengan data lainnya, hal ini dipergunakan untuk membuktikan hipotesa. Analisa yang digunakan adalah SPSS dengan Chi-Square dan diharapkan bahwa sampel-sampel acak yang ditarik dari populasi mencerminkan karakteristik dari populasi tersebut.

\section{Hasil dan Pembahasan}

Untuk meningkatkan kualitas lingkungan permukiman, dibutuhkan kegotongroyongan warga agar terwujud kampung yang hijau, bersih dan sehat. Dari hasil pengolahan data yang terdiri dari 100 RT yang disurvei, maka ratarata partisipasi masyarakat di kampung Gunung Anyar tinggi dalam melakukan penghijauan di masing-masing rumah.

Untuk pengelolahan sampah kering, dengan menggunakan $4 \mathrm{R}$ (reuse, reduce, recycle, dan repair), yaitu dengan pembentukan bank sampah dengan cara dipilah dan diolah menjadi berbagai suvenir maupun hiasan yang bernilai jual tinggi dan untuk sampah basah dibuat pupuk kompos, sedangkan untuk pengelolaan IPAL/teknologi water treatment, air bersih dan sanitasi lingkungan, hal ini cukup banyak RW-RW yang melakukannya.

\subsection{Meningkatkan partisipasi ma- syarakat dalam ekologi permuki- man}

Usaha-usaha yang dilakukan kampung Gunung Anyar untuk meningkatkan partisipasi masyarakat, adalah dengan menggerakkan kader lingkungan disetiap kecamatan. Untuk kampung yang masih membutuhkan sentuhan, yaitu dengan mengadakan sosialisasi yang intensif untuk menggerakkan warga kampung. Selain sosialisasi, juga mengadakan pelatihan untuk mewujudkan lingkungan yang hijau dan asri. Untuk menggerakkan warga, agar berpartisipasi demi lingkungan permukimannya, maka diperlukan pula peran pemerintah kota Surabaya.

\subsection{Meningkatkan kualitas lingku- ngan permukiman}

Partisipasi masyarakat dalam meningkatkan kualitas lingkungan permukiman adalah:

a. Pola penanaman urban farming dengan sistem hidroponik, yaitu menanam tumbuhan tidak menggunakan media tanah. Cukup dengan air dan tak perlu lahan luas, karena dibuat vertikal sesuai dengan konsep urban farming. Cara menanamnya pun mudah, yakni dengan menampung air mengalir dengan menggunakan pipa paralon. Kemudian air yang sudah dicampuri pupuk cair itu secara berkala diputar ke dalam sistem tersebut. Dengan demikian tanaman yang diletakkan di bagian atas bisa tumbuh (gambar 1).

b. Rumah pembibitan vertikal itu dibangun setinggi 2,5 meter. Bahan yang digunakan adalah besi galvalum. Rumah tersebut dibangun vertikal dengan kemiringan $60^{\circ}$. Selain tempat untuk meletakkan bibit-bibit tanaman, rumah pembibitan itu dilengkapi drainase atau sistem pengairan otomatis. Pipa-pipa disusun disetiap sudutnya (gambar 2). 


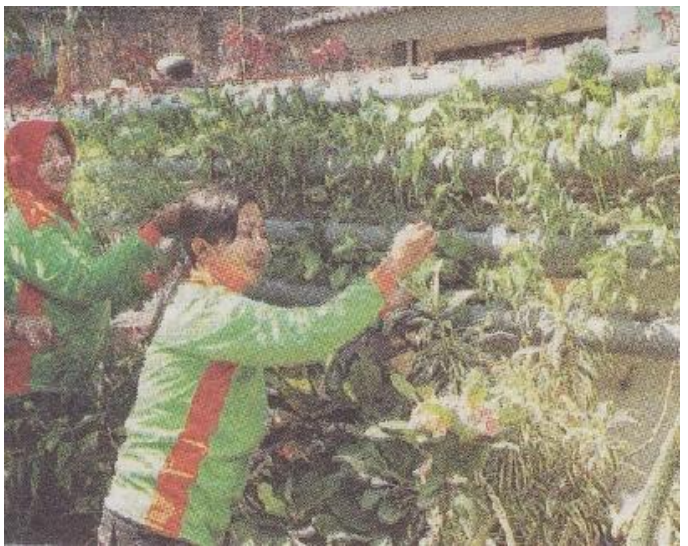

Gambar 1. Sawi dan bayam merah yang ditanam secara hidroponik.

Tujuan rumah pembibitan itu dibangun, untuk melihat penurunan suhu udara setelah penanaman. Hasilnya, suhu udara yang biasanya $32^{\circ}-35^{\circ}$ Celcius, bisa turun sekitar $4^{\circ}$ Celcius dan hasilnya ini bisa sampai dibawah $30^{\circ}$ Celcius, sehingga suasana jadi nyaman.

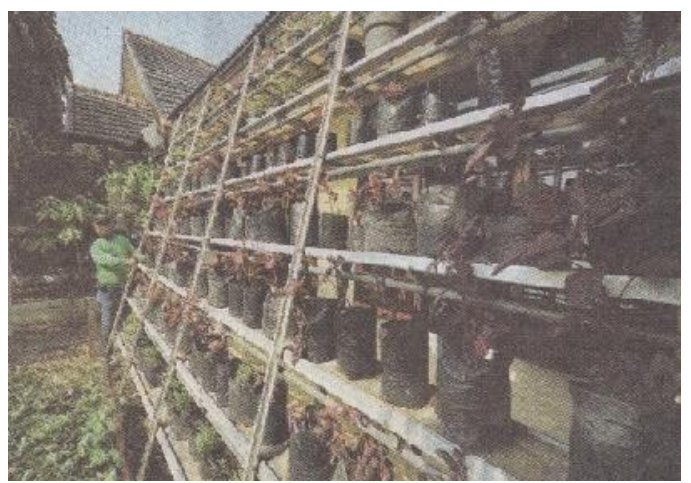

Gambar 2. Rumah pembibitan vertikal dengan kemiringan $60^{\circ}$

Meningkatkan kualitas lingkungan permukiman adalah dengan melindungi dan mengelola lingkungan permukiman, seperti pengelolahan sampah, IPAL/teknologi water treatment, air bersih, sanitasi lingkungan.

Dari hasil pengolahan data warga yang membuat pupuk kompos dari sampah basah, diantaranya membuat pupuk kompos di tabung plastik. Pupuk kompos tersebut dibuat dari sampah basah rumah tangga, seperti sisa nasi dan sayur; serta sampah lingkungan yang berupa dedaunan dan kulit buah-buahan. Semua sampah tersebut dimasukkan dalam tabung komposter. Total ada enam tabung komposter. Dengan tabung komposter yang memiliki volume 80 liter air, warga panen pupuk kompos tiap delapan bulan. Prosesnya adalah dengan melepas tali penahan, tabung lantas digulingkan. Hasil dari sampah basah tersebut kemudian dicampur dedak dan air gamping (kapur) secukupnya. Setelah itu, dikeringkan selama tiga hari. Keunggulan pupuk kompos adalah, jika pupuk biasa harus ditabur tiap empat bulan sekali, dan apabila menggunakan pupuk kompos cukup 6-8 bulan sekali dan pemakaian pupuk kompos ini cukup efektif, tinggal menyiram tanaman saja, tidak perlu sering memberikan pupuk.

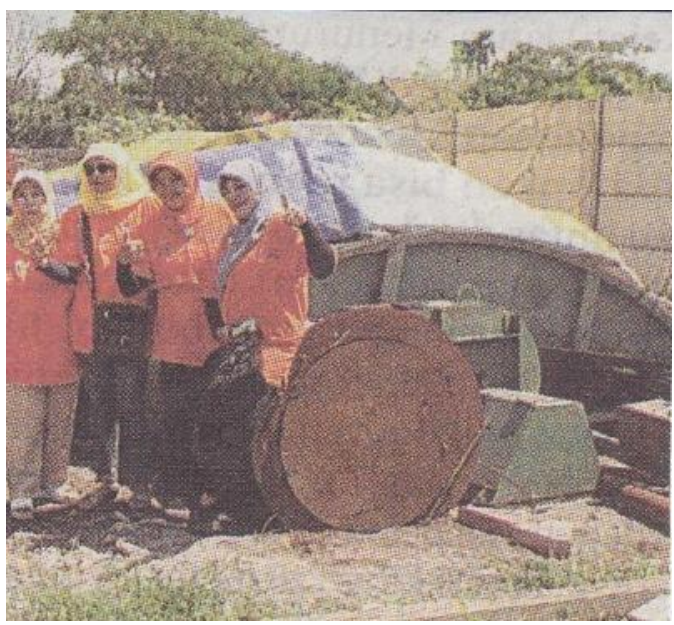

Gambar 3. Rumah kompos

Ada pula warga yang menggunakan teknologi modern yaitu dengan membangun rumah kompos atau peleburan 
sampah berskala besar dan terpusat (gambar 3). Luas bangunan rumah kompos adalah ( 8 x 25) meter. Teknologi modern tersebut mampu mengolah semua jenis sampah yang dihasilkan warga dan teknologi tersebut dibuat sendiri oleh salah seorang warga, sehingga pembuatannya tidak mengeluarkan banyak biaya. Ada beberapa warga mengolah sampah basah dengan sistem takakura (gambar 4).

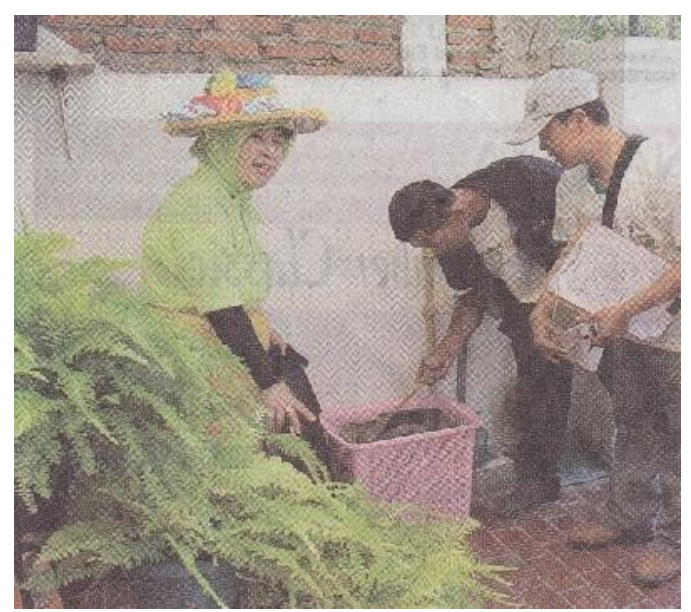

Gambar 4. Sistem pengomposan dengan menggunakan keranjang yang disebut takakura.

Proses pembuatan pupuk kompos dengan keranjang takakura:

- Siapkan hasil sampah dari takakura atau komposter.

- Campur dengan dedak dan air kapur.

- Diamkan selama tiga hari.

- Sebar pupuk ke pot-pot tanaman.

Keunggulan dari pupuk ini adalah kandungan unsur hara lebih baik. Tanah yang menggunakan pupuk ini bisa tahan 8-10 bulan tanpa ganti pupuk. Sedangkan warga yang membuat IPAL (instalasi pengolahan air limbah) secara swadaya. Pembuatan instalasi tersebut tidak kalah oleh buatan pabrik. Air hasil olahan sangat jernih dan tidak bau. Padahal, sumbernya dari selokan.

Caranya, air disaring dua kali, terdapat dua saringan. Setiap filter berisi pasir, ijuk, dan kerikil. Air hasil olahan lantas didistribusikan melalui pipa ke 12 titik. Hal ini juga menggunakan pipa sprinkler untuk mengalirkan air hasil IPAL. Saking jernihnya, air tersebut bisa dimanfaatkan untuk menyiram tanaman dan mencuci sepeda motor (gambar 5).

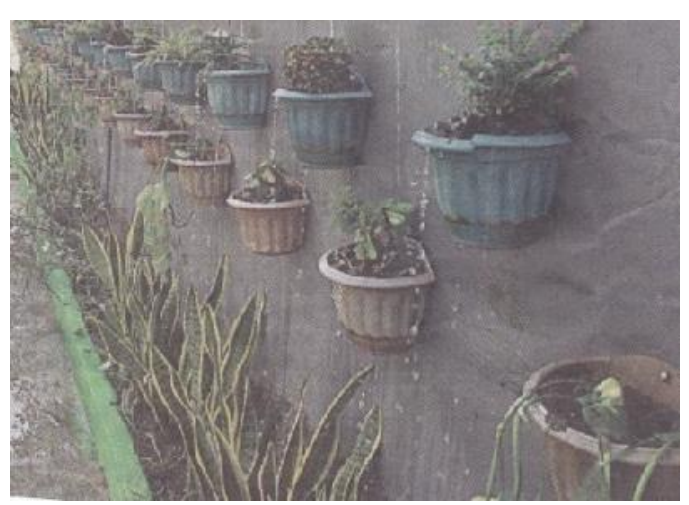

Gambar 5. Penggunaan pipa sprinkler untuk mengalirkan air hasil IPAL

Pengelolaan air limbah yang dibuat oleh warga ada yang diberi nama IPAL Alaska, yang merupakan singkatan dari air limbah asal kali, karena memang air yang diolah berasal dari kali di depan kampung. Namun karena teknologi yang digunakan masih sederhana, maka air hasil IPAL belum $100 \%$ jernih, sedangkan untuk menjernihkan air yang dihasilkan sebaiknya ditambah kaporit atau tawas, supaya lebih jernih dan tidak bau (gambar 6).

Pada tahun 2012, dapat bantuan mesin Water Treatment, agar hasil pengolahan air limbahnya lebih jernih, selain itu tinggi tandon air ditambah 4 meter seperti gambar 7. Dengan demikian air 
yang dihasilkan dapat dimanfaatkan secara luas.

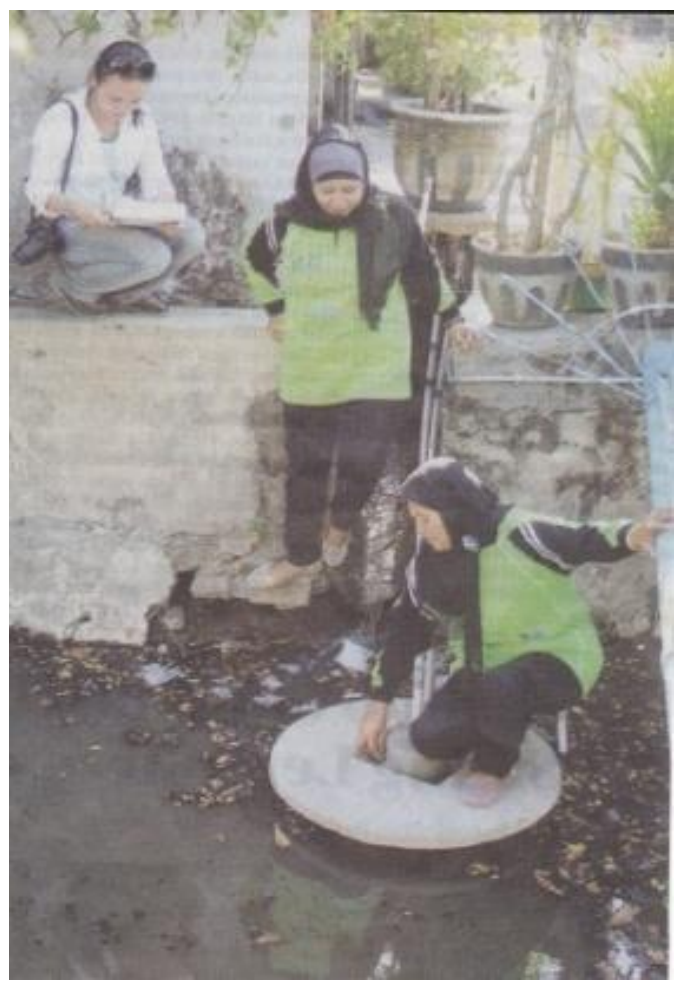

Gambar 6. Kondisi IPAL Alaska (air limbah asal kali)

Warga mengolah air limbah dengan membuat IPAL, kemudian hasil dari IPAL disalurkan ke tandon atas untuk dipanaskan menggunakan energi matahari (gambar 8). Hasilnya disalurkan ke rumah-rumah warga yang membutuhkan untuk mandi.

\section{Simpulan}

Dari penelitian ini dapat disimpulkan adalah sebagai berikut:

a. Untuk meningkatkan partisipasi masyarakat, maka usaha-usaha yang dilakukan kampung Gunung Anyar adalah dengan melakukan sosialisasi yang intensif dan peran serta Pemerintah Kota Surabaya, yaitu dengan mengadakan lomba
Surabaya Cantik Green and Clean yang diadakan setiap tahun.

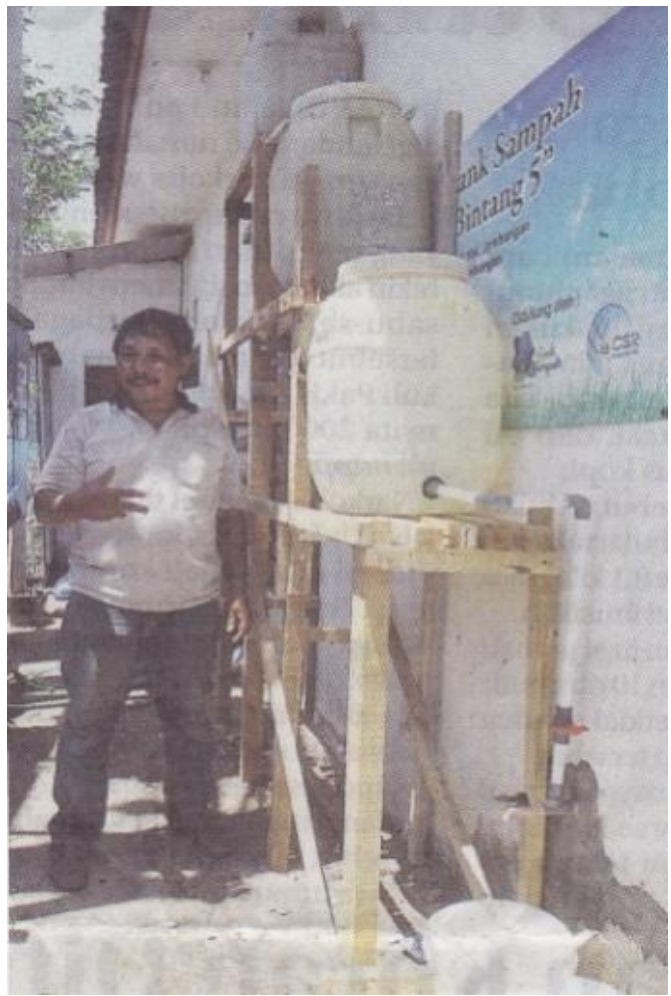

Gambar 7. Kondisi tandon air dengan ketinggian 4 meter

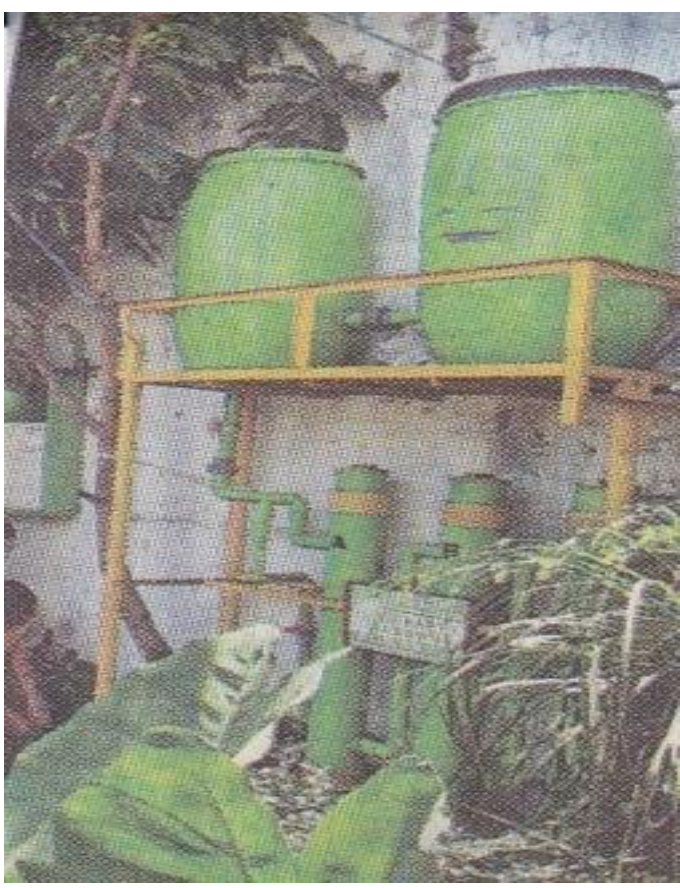

Gambar 8. Kondisi tandon untuk pemanas air menggunakan energi matahari 
b. Untuk meningkatkan kualitas lingkungan permukiman, maka warga membuat karya yang inovatif yaitu rumah pembibitan vertikal yang difungsikan untuk penghijauan dan dapat mendinginkan bagian dalam ruang, sehingga suhunya dapat turun sekitar $4^{\circ}$ Celsius.

c. Beragam usaha pelatihan digencarkan termasuk pemahaman kepada warga tentang pengelolaan lingkungan permukimannya, agar warga bisa bangkit, sehingga jumlah pengangguran dari warga yang sebelumnya mencapai $40 \%$ dapat turun menjadi $5 \%$.

d. Untuk memanfaatkan sampah dapur warga membuat pupuk kompos di tabung plastik, rumah kompos, sistem pengomposan dengan menggunakan keranjang yang disebut takakura.

e. Untuk menyiram tanaman dan mandi, warga mengolah limbah secara sederhana sehingga air dapat menyaring air kali yang kotor menjadi air yang jernih.

\section{Daftar Pustaka}

A Guide to Agenda 21. (1992). The Global Partnership. Genewa: UNCED.

Carl, Batone dkk. (1992). Environmental Management and Urban Development.

Goestaf, Abas. (1992). Perencanaan Wilayah Dengan Konsep Tata Arsitektur Yang Berwawasan Lingkungan. Jakarta: APK.
National Committee for Habitat II. (1996). National Report for Habitat II. Jakarta.

Silas, Johan. (1985). Perumahan Dan Permukiman, jilid 1 dan 2, Jurusan Arsitektur, FTSP-ITS. Surabaya.

Rapoport Amos. (1994). Sustainability, Meaning And Traditional Environments dalam Traditional Dwellings and Settlements Working Paper Series, Editor Nezar Alsayyad IASTE seri 75 Center for Environmental Design Research University of California. Berkeley.

Undang-Undang Republik Indonesia Nomor 4. (1992). Perumahan dan Permukiman. Direktorat Jenderal Cipta Karya-DPU.

Jurnal APLIKASI: Media Informasi \& Komunikasi Aplikasi Teknik Sipil Terkini Halaman 63 
Halaman ini sengaja dikosongkan 